\title{
PENGARUH MATERIAL BEARING TERHADAP KONSUMSI BAHAN BAKAR MOBIL HEMAT ENERGI TARSIUS GV-1
}

\author{
Eka Sari Wijianti ${ }^{1}$, Saparin $^{2}$ \\ 1,2 Jurusan Teknik Mesin, Fakultas Teknik, Universitas Bangka Balitung \\ Kampus Terpadu Desa Balunijuk Kecamatan Merawang Kabupaten bangka \\ email : ekasariwijianti@yahoo.co.id
}

\begin{abstract}
Abstrak
Penelitian ini difokuskan pada fungsi bearing dan poros roda pada kendaraan bermotor. Bearing berfungsi sebagai penumpu poros yang berputar dengan putaran tinggi. Material bearing memberikan pengaruh terhadap daya gelinding kendaraan. Oleh karena itu penelitian ini akan membahas tentang pengaruh material bearing terhadap konsumsi bahan bakar pada mobil hemat energi yang bernama Tarsius GV milik mahasiswa Teknik Mesin Universitas Bangka Belitung. Pengujian dilakukan di lintas timur Pantai Koala Kabupaten Bangka dengan mengambil jarak tempuh sejauh 2,2 km. Material bearing yang diuji adalah bearing dengan bahan keramik dan baja tipe 6000, dimana diameter inner (ID) $10 \mathrm{~mm}$, diameter outer (OT) $26 \mathrm{~mm}$ dan lebar bearing (width) $8 \mathrm{~mm}$. Poros yang digunakan adalah poros berdiameter $10 \mathrm{~mm}$, suaian antara poros dan bearing adalah suaian clearence tipe easy sliding fit $h 7$. Hasil pengujian menunjukkan bahwa bearing dengan material keramik menunjukkan hasil yang lebih optimal. Untuk jumlah bahan bakar, bearing keramik hanya membutuhkan $16,77 \mathrm{ml}$ untuk jarak tempuh $2,2 \mathrm{~km}$, sedangkan bearing baja membutuhkan $18,67 \mathrm{ml}$. Sehingga konsumsi bahan bakar untuk bearing keramik mencapai 132,32 km/liter sedangkan bearing baja adalah 118,80 km/liter.
\end{abstract}

Kata kunci: bearing, konsumsi bahan bakar, mobil hemat energi

\begin{abstract}
This study focused on the function of bearings and wheel shafts on motorized vehicles. The bearing functions as a supporting shaft that rotates with high rotation. Bearing material has an effect on vehicle rolling power. Therefore, this study will discuss the influence of bearing material on fuel consumption in energy-efficient cars called Tarsius GV owned by Mechanical Engineering students of Bangka Belitung University. The test was carried out in the eastern crossing of Koala Beach, Bangka Regency, taking a distance of $2.2 \mathrm{~km}$. The bearing material tested is bearing with ceramic and steel type 6000, where the inner diameter $(I D)$ is $10 \mathrm{~mm}$, outer diameter $(O T)$ is $26 \mathrm{~mm}$ and the width of the bearing (width) is $8 \mathrm{~mm}$. The shaft used is a 10mm diameter shaft, the alignment between the shaft and bearing is a clear type of easy sliding fit $h 7$. The test results show that bearings with ceramic material show more optimal results. For the amount of fuel, ceramic bearings only need $16.77 \mathrm{ml}$ for $2.2 \mathrm{~km}$ distance, while steel bearings require $18.67 \mathrm{ml}$. So that the fuel consumption for ceramic bearings reaches 132.32 $\mathrm{km} /$ liter while steel bearing is $118.80 \mathrm{~km} /$ liter.
\end{abstract}

Keywords: bearing, fuel consumption, energy saving car

\section{PENDAHULUAN}

Bahan bakar yang tidak boros menjadi salah satu target untuk semua kendaraan bermotor. Banyak hal dilakukan untuk mencapai tujuan ini. Mulai dari desain aerodinamis bodi, material yang ringan, sistem mekanik yang efisien, sistem mekanik roda yang minim gesekan dan lain sebagainya. semua dilakukan dengan orientasi adalah efisiensi bahan bakar.
Afriansyah (2015) dalam penelitiannya tentang perancangan poros roda depan mobil menyatakan bahwa kenderaan roda berfungsi untuk menopang berat motor dan pengendara, menyalurkan daya dorong, pengereman, daya stir pada jalan. Disaat yang sama roda juga menyerap tekanan/kejutan dari permukaan jalan. Pada sepeda motor roda berfungsi untuk menopang berat motor dan pengendara pada area yang kecil dimana permukaan ban menyentuh permukaan jalan, menyalurkan daya dorong, pengereman, daya stir pada jalan. Untuk itu roda harus bersifat kuat, kaku/rigit dan ringan.

21 Wijianti, Eka Sari, dkk; Pengaruh Material Bearing Terhadap Konsumsi Bahan Bakar Mobil Hemat Energi Tarsius Gv-1 
Ada tiga bagian roda pada sepeda motor, yaitu bagian hub roda, bagian pelek roda (wheel rim), dan ban (tire). Pada hub roda terpasang bantalan peluru (bearing), sepatu rem, tromol dan komponen bantu lainnya. Afriansyah jga menyatakan bahwa rolling element bearing dipasang pada frame poros dengan memanfaatkan suaian press. Dibutuhkan step pada poros untuk menahan bearing. Snap ring digunakan untuk mencegah pergerakan aksial poros terhadap bearing.

Bearing merupakan komponen yang mempunyai fungsi sangat penting pada kendaraan bermotor. Bearing berfungsi sebagai penumpu poros yang berputar. Pada dasarnya, fungsi bearing adalah menjaga agar poros ban (as roda) tidak langsung bergesekan dengan rumah (roda). Komponen ini juga didesain minim friksi, sehingga ketika roda berputar bisa terjaga stabil. Ujungnya, adalah level keborosan suatu sepeda motor bisa lebih irit atau sebaliknya boros. Jadi makin efisien penggunaan bahan bakar minyak (BBM), karena putaran yang lebih ringan. Seperti dijelaskan dalam penelitian Junkang Guo (2013) bahwa pada desain mesin yang berputar, presisi putar biasanya merupakan isu pertama yang menentukan performance mesin. Ketepatan putaran dipengaruhi oleh banyak faktor, seperti desain toleransi, proses perakitan dan deformasi.

Salah satu faktor yang juga mempengaruhi performa bearing adalah material bearing tersebut. Ada bermacam-macam material bearing seperti keramik, carbon steel, stainless steel, chrome steel, brass, aluminium, tungsten carbide, platinum, gold, titanium dan lain sebagainya. Penggunaan material tersebut disesuaikan dengan kondisi konstruksi dan fungsinya.

Bearing yang akan digunakan pada penelitian ini adalah bearing sebagai bantalan poros mobil. Kendaraan yang dijadikan objek adalah mobil hemat energi milik mahasiswa Jurusan Teknik Mesin Fakultas Teknik Universitas Bangka Belitung. Dengan pemilihan jenis material bearing yang tepat diharapkan mobil dapat mencapai efisiensi bahan bakar yang optimal.

\section{METODE PENELITIAN}

Penelitian ini adalah penelitian eksperimen. Penelitian dilakukan pada mobil hemat energi yang bernama Tarsius GV-1 yang dibangun oleh Mentilen Team 1 yang akan diikutsertakan pada kontes mobil hemat energi kategori bahan bakar bensin tahun 2018 .

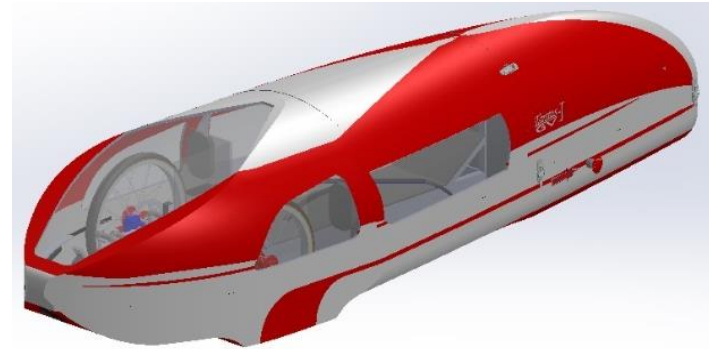

Gambar 1 Mobil hemat energi Tarsius GV-1

Bearing yang akan digunakan adalah keramik dengan tipe ball bearing seri 6000 yang memiliki diameter yang sama dengan poros yaitu inner $10 \mathrm{~mm}$ (ID), outer $26 \mathrm{~mm}$ (OD) dan tebal $8 \mathrm{~mm}$ (B). Sedangkan poros yang digunakan adalah diameter $10 \mathrm{~mm}$ dengan bahan baja.

Material bearing divariasikan menjadi 2 macam:

1. Ball bearing bahan keramik

2. Ball bearing bahan baja

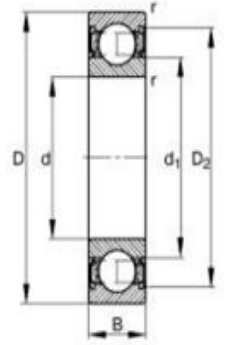

a.

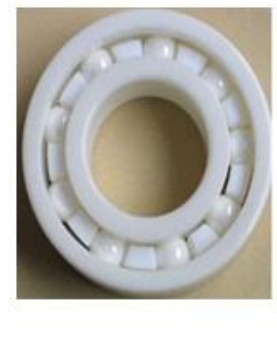

b.

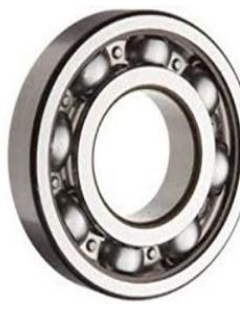

c.
Gambar 2 Ball bearing tipe 6000 a. Dimensi b. Keramik c. Baja

Pengujian dilakukan secara eksperimental, dimana mobil dibangun dan dirakit sesuai dengan rancangan yang telah dibuat.. Kemudian diuji performance mobil untuk mengetahui berapa jumlah bahan bakar yang dihabiskan untuk menempuh jarak $2,2 \mathrm{~km}$. Engine mobil menggunakan mesin dengan kapasitas $125 \mathrm{cc}$. Setelah diketahui jumlah bahan bakar yang dihabiskan, kemudian dihitung konsumsi bahan bakar mobil.

Prosedur Pengujian

1. Pastikan tanki bahan bakar dalam keadaan kosong dengan memvacum saluran bahan bakar hingga bersih.

2. Siapkan bahan bakar bensin (pertamax) sebanyak 100ml, masukkan kedalam fuel tank.

3. Berikan tekanan hingga bahan bakar memenuhi saluran bahan bakar menuju ruang bakar.

4. Nyalakan mobil

5. Pacu mobil sampai kecepatan $70 \mathrm{~km} / \mathrm{jam}$, kemudian matikan mesin, biarkan mobil menggelinding.

6. Nyalakan kembali mobil apabila mencapai kecepatan $20 \mathrm{~km} / \mathrm{jam}$ dan pacu kembali hingga 
kecpatan $70 \mathrm{~km} / \mathrm{jam}$, kemudian biarkan menggelinding.

7. Lakukan point 5 dan 6 sampai mobil mencapai jarak tempuh $2,2 \mathrm{~km}$.

Perhitungan Bahan bakar

1. Ambil bahan bakar sisa yang terdapat pada tank fuel.

2. Tuangkan ke dalam gelas ukur.

3. Hitung jumlah bahan bakar yang masih tersisa

$T_{b b}=T_{a}-T_{e}$

$\mathrm{T}_{\mathrm{bb}}=$ Jumlah bahan bakar yang digunakan (ml)

$\mathrm{T}_{\mathrm{a}}=$ jumlah bahan bakar awal (ml)

$\mathrm{T}_{\mathrm{b}}=$ jumlah bahan bakar sisa $(\mathrm{ml})$

\section{Hasil dan Pembahasan}

Hasil penelitian pada tabel 1 menunjukkan bahwa waktu pengujian bervariasi, artinya jumlah bahan bakar yang digunakan juga dipengaruhi oleh waktu pengujian. Jumlah bahan bakar yang digunakan menggunakan bearing baja lebih banyak dibandingkan menggunakan bearing keramik. sedangkan untuk jumlah bahan bakar yang digunakan bearing dengan jenis baja lebih banyak menghabiskan bahan bakar dibandingkan dengan penggunaan jenis keramik. Untuk bearing baja ratarata bahan bakar yang digunakan adalah $18,67 \mathrm{ml}$ sedangkan untuk bahan keramik rata-rata $16,77 \mathrm{ml}$. Berdasarkan hasil perhitungan pada tabel 2, bahwa jumlah konsumsi bahan bakar untuk bearing bertipe keramik mencapai $132 \mathrm{~km} /$ liter sedangkan untuk tipe baja hanya mencapai $118 \mathrm{~km} / \mathrm{liter}$.

Tabel 1 Data hasil penelitian

\begin{tabular}{|c|c|c|c|c|c|c|c|c|}
\hline \multirow{2}{*}{ No } & \multirow{2}{*}{ Bearing } & \multicolumn{3}{|c|}{ Waktu (detik) } & \multirow{2}{*}{$\begin{array}{l}\text { Rata-rata } \\
\text { (detik) }\end{array}$} & \multicolumn{2}{|c|}{$\begin{array}{l}\text { Jumlah bahan bakar } \\
\text { yang digunakan }(\mathrm{ml})\end{array}$} & \multirow{2}{*}{$\begin{array}{l}\text { Rata-rata jumlah } \\
\text { bahan bakar (ml) }\end{array}$} \\
\hline & & 1 & 2 & 3 & & $1 \quad 2$ & 3 & \\
\hline 1. & Steel & 5.09 & 4.38 & 3.38 & 4,28 & 17 & 18 & 18,67 \\
\hline 2. & Keramik & 3.34 & 3.52 & 3.37 & 3,41 & 15.8 & 15.5 & 16,77 \\
\hline
\end{tabular}

Tabel 2 Jumlah konsumsi bahan bakar

\begin{tabular}{|c|c|c|c|c|c|c|c|c|}
\hline \multirow[t]{2}{*}{ No } & \multirow[t]{2}{*}{ Bearing } & \multicolumn{3}{|c|}{$\begin{array}{l}\text { Bahan bakar yang } \\
\text { digunakan }(\mathrm{ml})\end{array}$} & \multicolumn{3}{|c|}{ Konsumsi bahan bakar (km/l) } & \multirow{2}{*}{$\begin{array}{l}\text { Rata-rata Konsumsi } \\
\text { Bahan Bakar }(\mathrm{km} / \mathrm{l})\end{array}$} \\
\hline & & 1 & 2 & 3 & 1 & 2 & 3 & \\
\hline 1. & & 21 & 17 & 18 & 104,76 & 129,41 & 122,22 & 118,80 \\
\hline 2. & Steel & 19 & 15.8 & 15.5 & 115,79 & 139,24 & 141,94 & 132,32 \\
\hline
\end{tabular}

Konsumsi bahan bakar terbaik adalah material bearing dengan jenis keramik. Jenis material ini memiliki karakteristik anti magnetik isolasi, tahan abrasi, bebas minyak pelumas dan tahan pada suhu tinggi atau rendah sekalipun. Material keramik memiliki modulus elastisitas yang lebih tinggi dari baja, bahan yang lebih ringan dan kemampuan mencapai RPM yang lebih tinggi sehingga lifetime lebih baik. Material yang ringan ini menyebabkan gesekan yang sangat minim sehingga daya gliding yang dimiliki mobil menjadi lebih baik, sehingga jarak tempuh mobil menjadi lebih panjang. Kondisi ini dibuktikan dengan jarak tempuh 2,2 km, driver hanya menghidupkan engine sebanyak 3 kali, selebihnya adalah memanfaatkan gaya gelinding. Kondisi ini menyebabkan konsumsi bahan bakar yang diperlukan lebih sedikit.

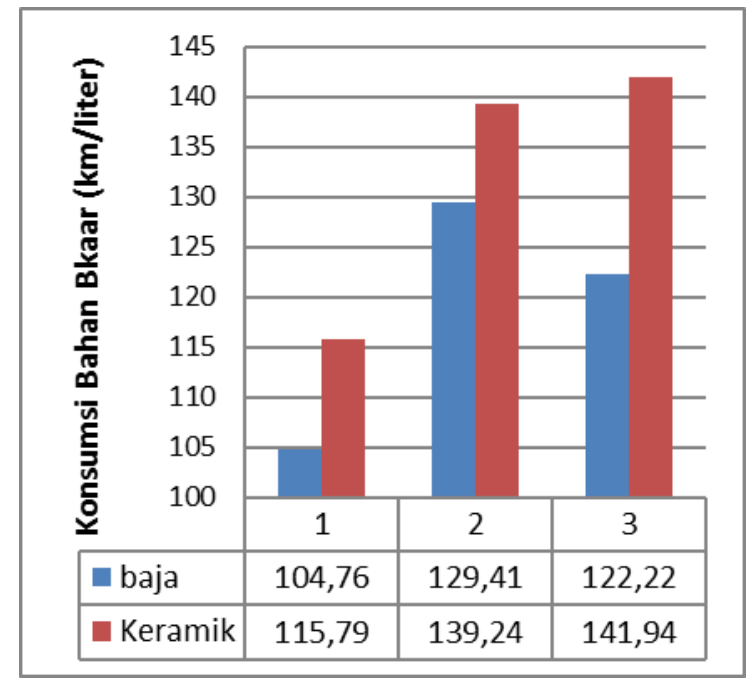

Gambar 3 Grafik konsumsi bahan bakar

Dari gambar 3 dapat dilihat bahwa seiring dengan penggunaan material bearing, bahwa konsumsi bahan bakar paling irit yang diperlukan 
untuk menempuh jarak 2,2 km di dapat pada jenis toleransi dengan suaian sangat longgar. Daya gliding mobil menjadi lebih ringan ketika dudukan bearing pada poros dipasang pada toleransi yang sangat longgar. Untuk jarak tempuh 2,2 km tersebut, rata-rata bahan bakar yang dibutuhkan hanya $16,77 \mathrm{ml}$ sehingga konsumsi bahan bakar mencapai $132,32 \mathrm{~km} /$ liter. Sedangkan untuk toleransi pas, kebutuhan bahan bakar rata-rata adalah 18,67 ml dengan hitungan konsumsi bahan bakar 118,80 $\mathrm{km} / \mathrm{liter}$.

\section{UCAPAN TERIMAKASIH}

Terima kasih kepada Universitas Bangka Belitung yang telah memberikan konstribusi dalam pendanaan penelitian ini dalam Program Penelitian Dosen Tingkat Jurusan dengan skema pendanaan tahun 2018.

\section{KESIMPULAN}

Penelitian tentang poros dan bearing pada mobil hemat energi Tarsius GV-1 dengan mesin 125 cc telah dilakukan. Material bearing yang digunakan untuk penelitian adalah bearing dengan material baja dan keramik. Bearing tipe ini mampu menahan beban kecil dengan putaran yang tinggi. Dimensi bearing yang digunakan adalah inner $10 \mathrm{~mm}$, outer $26 \mathrm{~mm}$ dan lebar $8 \mathrm{~mm}$. Sedangkan poros yang digunakan adalah diameter $10 \mathrm{~mm}$. Hasil pengujian menunjukkan bahwa hasil terbaik didapatkan oleh bearing dengan tipe keramik. Hasil pengujian menunjukkan bahwa mobil memiliki daya gelinding yang maksimal dan pada jarak tempuh $2,2 \mathrm{~km}$, mobil hanya menghabiskan bahan bakar rata-rata $16,77 \mathrm{ml}$, sehingga konsumsi bahan bakar optimal adalah 118 $\mathrm{km}$ per liter.

\section{DAFTAR PUSTAKA}

[1] Afriansyah, Rahmawati (2015), Perancangan Poros Roda Depan Untuk Mobil Harapan Dan Analisa Simulasi Pembebanan Statik Menggunakan Perangkat Lunak Ansys 14.0, Jurnal Biltek Sekolah Tinggi Teknik Harapan Medan, Vol. 5, No.005 Tahun 2015.

[2] Arif Rahman Saleh (2014), Analisa Kerusakan Bantalan Bola (Ball Bearing) Jenis Deep Groove Pada Lori Pabrik Kelapa Sawit Dan Cara Penanggulangannya, JURNAL APTEK Jurusan Teknik Mesin Universitas Pasir Pengaraian, Vol. 6 No. 1 Januari 2014.

[3] James R. Thrower (1986), Technical Statics and Strength of Materials, Second Edition, Delmar Publisher INC, New York United States of America.

[4] Junkang Guo et all (2013), A tolerance analysis method for rotating machinery, 12th CIRP Conference on Computer Aided Tolerancing, Procedia CIRP 10 ( 2013 ) $77-83$.

[5] Joni Dewanto, dkk (2003), Permodelan Sistem Gaya dan Traksi Roda, Jurnal Teknik Mesin Universitas Kristen Petra, Vol.5 No.2, Oktober 2003:64-69.

[6] YU Yongjian et all (2017), Research on Rotational Accuracy of Cylindrical Roller Bearings, 10th CIRP Conference on Intelligent Computation in Manufacturing Engineering CIRP ICME '16, Procedia CIRP 62 ( 2017 ) 380 -385 . 